For the Journal of the Franklin Institute.

\title{
Particulars of the U.S. Steam Sloop Pocahontas.
}

Hull built by U.S. Government at Gosport Navy Yard. Machinery originally built by Harrison Loring, of Boston; rebuilt at the Gosport Navy Yard.

HULS-

Length from knighthead to taffrail, " on load water line,

Breadth of beam, extreme, .

Depth of hold,

Length of engine and boiler space,

Draft of water,

Displacement at load draft, .

'lonnage,

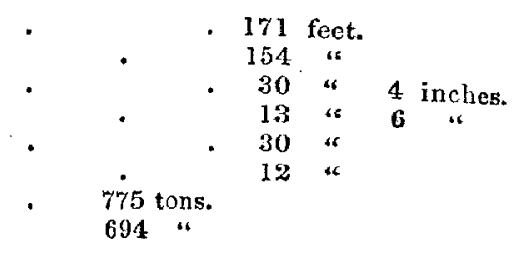

ExGnes.-Two-Vertical direct action.

Diameter of cylinder,

Length of struke, ?

Diameter of shaft,

Cut-off-fixed slide-half-stroke.

Maximum pressure of steam,

" revolutions,

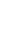

2 feet $\begin{array}{cc}33 & \text { inches. } \\ 6 & 4 \\ 8 & 4\end{array}$

20 lbs.

70.

Borlens.-Two-Martin's vertical tubular.

Length of boilers,

Width

Height

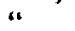

exclusive of steam

Furnaces in each boiler,

Brealth of furnace,

length of grate bars,

Number of tubes (iron)

Iength of tube,

External diameter, .

Grate surface,

Heating surface,

Diameter of smoke pipe,

Height

above grates,

SCrEW,-Uniform.

Diameter,

Length at hub,

Pitch, " periphery,"

Number of blades,

Remarks.-During a trial at sea, March 27, 1860, speed 8 knots. Revolutions, 59. Steam, 15 los. J. H. W.

\section{Effect of Pressure on Electro-conducting Power.}

M. Elie Wartmann has found experimentally that the electric conductibility of copper wire is sensibly diminished by a pressure of 50 atmospheres, that this diminution increases with the pressure, and disappears when the pressure is relieved. The experiments were carried up to 400 atmospheres. These results establish a new analogy between heat, light, and electricity. - L'Institut. 